\title{
Accuracy of enteral syringes with commonly prescribed paediatric oral liquid medicines
}

Arenas-Lopez S, Gurung K, Tibby SM, Calleja-Hernandez MA, Tuleu C

Sara Arenas-López, Consultant Pharmacist Paediatric Critical Care, Evelina London Children's Hospital, Guy's \& St Thomas NHS Foundation Trust, Westminster Bridge Road, London SE1 7EH

Tel: +442071885049 Email: sara.arenas@gstt.nhs.uk

Karuna Gurung, MRPharm Student, UCL School of Pharmacy, London, United Kingdom

Shane M Tibby, PICU Consultant, Evelina London Children's Hospital, London SE1 7EH Email: shane.tibby@gstt.nhs.uk

Miguel-Angel Calleja-Hernández, Director Pharmacy Service, Hospital Universitario Virgen de las Nieves and Professor at University of Granada, Spain. Email: mangel.calleja.sspa@juntadeandalucia.es

Catherine Tuleu (Corresponding author), Reader in Pharmaceutics, UCL School of Pharmacy, London, United Kingdom c.tuleu@ucl.ac.uk

Keywords: Accuracy-volume-enteral-syringes-liquid-paediatrics-device

Word count - Original article: 2482 


\section{ABSTRACT (273 Words)}

Aim:

To investigate the paediatric volumetric accuracy for two enteral syringe brands, using commercially available liquid drug formulations, across a range of clinically relevant volumes and physicochemical properties.

\section{Method:}

In vitro experiment under laboratory conditions. Ten drug formulations were tested for two syringe brands (Baxa, Medicina) using a range of formulation volumes (0.05 to 5 $\mathrm{mL}$ ) and syringe sizes ( 1 to $5 \mathrm{~mL}$ ). The weight of syringes, empty, filled and after expelling liquids were accurately measured and converted into volume, based on the known formulation densities. Ten replications were performed for each combination of drug, syringe and volume. Accuracy of the delivered volume was expressed as a percentage of desired volume, with desired range being within $\pm 10 \%$ for all replications.

\section{Results:}

The two brands showed a different type of error, with Baxa demonstrating a slight positive bias (excess average volume delivered) at the smallest volumes tested in each syringe size, while Medicina had poorer precision (greater variability) at the smaller volumes (ANOVA 2- and 3-way interactions all $\mathrm{P}<0.005$ ). Using these results we were able to identify a lower limit for volume accuracy for each syringe size and each brand. Of note, the $1 \mathrm{~mL}$ syringe for both brands was inaccurate below volumes of $0.25 \mathrm{~mL}$. The physicochemical properties of $\mathrm{pH}$ (range 2.82 to 7.45), surface tension ( 30.2 to $86.7 \mathrm{mN} / \mathrm{m}$ ) and viscosity (2 to $299 \mathrm{mPaS}$ ) did not influence error in a discernible pattern.

\section{Conclusion:}

Volumetric dosing was inaccurate when the smallest volumes were used across all syringe sizes and brands. These volumes reflect those used in clinical practice; thus error could potentially be reduced by manufacturers revising formulation concentrations for certain drugs. 


\section{Introduction}

Paediatric medications are administered most commonly via the oral route, accounting for approximately $60 \%$ of hospital prescriptions in children. Although a variety of oral medications are available, liquid dosage forms are commonest, comprising approximately two thirds of hospital oral administrations ${ }^{1}$, They are appropriate for infants, and any child who has difficulty swallowing tablets or capsules. They also provide a means of adjusting the drug dose to patient's weight or surface area ${ }^{2-4}$.

There are two main factors with liquid formulations which may compromise paediatric drug dosing. The first concerns the preparation of the formulation, and includes issues such as uniformity of content of the product when the drug is suspended and not solubilised, unknown bioavailability of extemporaneously prepared products, and the use of potentially toxic excipients such as ethanol. The second aspect relates to the accuracy of administration device used; these include measuring spoons, oral droppers, dosing cups (some of which contain etched calibrations) and oral syringes 5,6 . The majority of studies indicate that oral syringes provide greater accuracy than other devices, if used correctly ${ }^{7-10}$.

A variety of Agencies and publications now recommend syringes as the preferred oral administration device for infants and children especially when volumes of less than $5 \mathrm{ml}$ are required, including the British National Formulary for Children, the United Kingdom (UK) National Service Framework for Children and the Council of the Canadian Academies ${ }^{11-13}$ In addition, it is recommended that syringes be specific for oral administration, rather than utilising those designed for parenteral use. ${ }^{14,15}$ In 
2007 in the UK, the National Patient Safety Agency issued a safety alert, recommending the use of clearly labelled oral/enteral syringes that (a) cannot be connected to parenteral lines, (b) are unable to accommodate needles by having female luer lock tips, and (c) can be differentiated from parenteral syringes via the use of colour, such as purple ${ }^{14}$. This is now standard practice in many UK hospitals. In addition, these syringes are often used in preference to product-specific syringes supplied by the manufacturer as part of the packaging for certain drugs, especially in hospital settings.

Currently, two brands of oral syringes predominate in the UK. Interestingly, two aspects that could potentially compromise accuracy of drug delivery with these syringes in paediatric clinical practice have not been evaluated to our knowledge. The first relates to physicochemical characteristics of liquid formulations for various drugs. Viscosity and surface tension, for example, can affect the dosing accuracy of administration devices; as demonstrated in a study with oral droppers ${ }^{16}$ The European Committee for Medicinal Product for Human use has acknowledged this, recommending that oral administration devices be suitable for drug dosage forms in terms of the characteristics of the liquid ${ }^{5}$. The second aspect is that therapeutic dosing requirements, and hence the administered formulation volume can vary greatly in paediatric patients. In practice, it can often be difficult to measure; hence must be rounded to the nearest syringe graduation to provide a practical volume ${ }^{17}$. However, the extent to which dose rounding can take place without clinical consequences depends on therapeutic window of drugs and the accuracy of administration devices ${ }^{18}$. Administration devices such as oral syringes can further increase the dose variability if they are not suitable for the specific drug/dose; this could lead to under dosing with diminished treatment efficacy or overdosing with potential for toxic effects ${ }^{19}$. 
With this in mind, the aim of our study was to evaluate the volumetric accuracy of drug delivery using two common oral syringe brands in the UK, over the range of syringe sizes, drug volumes, and liquid types (comprising viscosity, surface tension and $\mathrm{pH}$ ) which mirror clinical paediatric practice.

\section{METHODS}

Two common syringe brands which are licensed for enteral administration of drugs that comply with National Patient Safety Agency recommendations were evaluated. Medicina ${ }^{\circledR}$ syringes presented a wide tip and are of $1 \mathrm{ml}, 2.5 \mathrm{ml}$ and $5 \mathrm{ml}$ capacities (smallest graduations $0.01 \mathrm{ml}, 0.1 \mathrm{ml}$ and $0.2 \mathrm{ml}$ respectively) whereas Baxa ${ }^{\circledR}$ syringes had a narrower tip, and are of $1 \mathrm{ml}, 3 \mathrm{ml}$ and $5 \mathrm{ml}$ capacity and they present the same smallest graduations as the Medicina brand per syringe size. (See figure 1S online supplement)

\section{Materials:}

Ten oral liquid medicinal products were selected as representative of the formulations used in paediatric clinical practice, encompassing a broad range of viscosity, $\mathrm{pH}$ and surface tension. These were classified into:

- Aqueous liquid (Calcium carbonate BP suspension - Guy's \& St Thomas' NHS foundation trust; Amoxicillin sugar-free suspension $125 \mathrm{mg} / 5 \mathrm{ml}$ - Athlone laboratories limited; Peppermint water BP 1973 - Viridian Pharma Ltd; Nifedipine oral drops $\AA^{\circledR}$ - Ratiopharm and deionized water as control)

- Hydroalcoholic liquid (Digoxin elixir, Lanoxin®; Sodium Iron edetate elixir, Sytron®; Alfacalcidol oral drops, One Alpha®; Phenytoin suspension, Epanutin $\left.{ }^{\circledR}\right)$ 
- or Lipidic liquid (Cyclosporine solution, Neoral®; Ciprofloxacin suspension, Ciproxin®)

The $\mathrm{pH}$ was measured with a pH meter 209 Hanna®. A rotational rheometer (Gemini $\mathrm{HR}{ }^{\text {nano }}$ by Malvern) was used to derive the viscosity at a shear rate at $100 \mathrm{~s}^{-1}$. Surface tension measurements were carried out on a Delta-8 multichannel microtensiometer (Kibron Inc.) and conductivity on a Primo 5 Hanna ${ }^{\circledR}$ Conductivity meter. Baseline measurements of the physicochemical properties for each formulation ( $\mathrm{pH}$, viscosity and surface tension) were made at room temperature in triplicate.

\section{Measurements of volume accuracy:}

Ten measurements were made for each combination of syringe brand, syringe size, type of drug and formulation volume. The results are expressed as mean percentage $( \pm S D)$ of the expected capacity indicated by the graduations. Accurate dosing was defined as within $10 \%$ of the intended volume $(17,20)$. The weight of the syringes' content was measured with a Balance Precisa ${ }^{\circ} 180 \mathrm{~A}$ [accuracy of $0.002 \mathrm{~g}$ with readability and repeatability of $0.1 \mathrm{mg}$ and linearity of 0.2 $\mathrm{mg}$ ] by subtracting the weight of the filled syringe and the weight of the syringe after expelling the liquid.

This weight was then converted into volume using the density:

$$
\text { density }(\mathrm{g} / \mathrm{ml})=\operatorname{mass}(\mathrm{g}) / \text { volume }(\mathrm{ml})
$$

The density was determined experimentally $(n=3)$ at room temperature for all liquids by weighing $5 \mathrm{ml}$ in a clean and dry tarred measuring cylinder (capacity $10 \mathrm{ml}$ ). 
All ten drug formulations were measured in the $1 \mathrm{ml}$ syringes. Six formulations (Lanoxin, Amoxicillin, Ciproxin, Peppermint water, Calcium Carbonate BP, Sytron) were measured in the medium size syringes $(2.5 \mathrm{ml}$ and $3 \mathrm{ml})$, and only five medicines (Amoxicillin, Ciproxin, Peppermint water, Calcium Carbonate BP, Sytron) were measured with the largest syringe size $(5 \mathrm{ml})$. Water was used as control. This was in order to mimic clinical doses administered in practice. Table $1 \mathrm{~S}$ (electronic supplement) describes the range of volumes measured for each syringe size.

\section{Statistical Analyses}

Unadjusted data are expressed as mean +/- standard deviation. The relationships between syringe brand, syringe size and formulation volume were evaluated using factorial analysis of variance (ANOVA). Brand, syringe size and formulation volume were treated as categorical variables, and the outcome variable (\% desired volume actually delivered) was modelled as continuous. All 2- and 3-way interactions were assessed as part of the ANOVA. This approach was taken to assess whether the relative error between brands differed according to syringe size and volume. To test whether the formulations' physicochemical properties affected accuracy of delivery, we undertook multiple linear regression using the $1 \mathrm{ml}$ syringe size only, testing interactions between formulation volume, brand and each of the physicochemical properties (surface tension, viscosity and $\mathrm{pH}$ ). Post hoc differences following ANOVA and regression were evaluated using marginal means with $95 \%$ confidence intervals. Analyses were performed using Stata v13.1 (StataCorp, Texas).

\section{RESULTS}


As expected, the dead space differed between brands. Medicina (wider tip) showed approximately double the dead space volume than Baxa (narrower tip) across each syringe size: $1 \mathrm{~mL}(0.11 \pm 0.01$ versus $0.06 \pm 0.003, p<0.001), 2.5 / 3 \mathrm{~mL}(0.13 \pm 0.01$ versus $0.06 \pm 0.01, p<0.001)$, and $5 \mathrm{~mL}(0.15 \pm 0.02$ versus $0.09 \pm 0.02, p<0.001)$.

Table 1 shows the physico-chemical characteristics of the formulations. The ranges for each property were: $\mathrm{pH}$ (2.82 to 7.45$)$, surface tension $(30.2$ to $86.7 \mathrm{mN} / \mathrm{m})$ and viscosity (2 to $299 \mathrm{mPaS}$ ).

Table 1: Physicochemical characteristics of the oral liquids. Results are shown as mean (SD) of triplicate measurements

\begin{tabular}{lccc} 
& $\mathrm{pH}$ & $\begin{array}{c}\text { Surface Tension } \\
(\mathrm{mN} / \mathrm{m})\end{array}$ & $\begin{array}{c}\text { Viscosity } \\
(\mathrm{mPaS})\end{array}$ \\
\hline Deionized water & $5.56( \pm 0.19)$ & $71.7( \pm 0.3)$ & $2.0( \pm 0.1)$ \\
Aqueous Liquid & & & \\
Calcium Carbonate & $7.09( \pm 0.01)$ & $79.1( \pm 3.9)$ & $82.3( \pm 1.0)$ \\
Amoxicillin 125mg/5mI SF & $4.70( \pm 0.02)$ & $86.7( \pm 0.7)$ & $68.7( \pm 1.9)$ \\
Peppermint water BP 1973 & $6.36( \pm 0.00)$ & $64.4( \pm 0.5)$ & $87.0( \pm 1.9)$ \\
Nifedipine & $7.45( \pm 0.18)$ & $40.2( \pm 1.2)$ & $56.1( \pm 1.7)$ \\
Hydroalcoholic Liquid & & & \\
Lanoxin-PG ELIX (Digoxin) & $7.01( \pm 0.01)$ & $38.0( \pm 0.8)$ & $5.7( \pm 0.5)$ \\
Sytron Elix & $2.82( \pm 0.01)$ & $60.5( \pm 0.3)$ & $5.3( \pm 0.2)$ \\
One-alpha (Alfacalcidol) & $6.99( \pm 0.01)$ & $30.2( \pm 2.3)$ & $9.7( \pm 0.7)$ \\
Epanutin (phenytoin) & $5.07( \pm 0.01)$ & $78.8( \pm 0.5)$ & $299.1( \pm 6.1)$ \\
Lipidic Liquid & & & \\
Neoral oral solution (cyclosporin) & $7.20( \pm 0.17)$ & $33.7( \pm 0.6)$ & $144.1( \pm 0.8)$ \\
Ciproxin suspension 250mg/5ml & $5.15( \pm 0.02)$ & $30.5( \pm 0.7)$ & $82.6( \pm 6.1)$
\end{tabular}

In terms of overall volumetric accuracy, all 2- and 3-way interactions between brand, syringe size and formulation volume were significant (table 2S, electronic 
supplement). This is shown by the ANOVA-estimated marginal means in figure 1 , whereby the error is not consistent between all combinations of brand, syringe size and formulation volume.

Here, the Medicina syringes showed acceptable (i.e. $<10 \%$ ) average volume delivery errors across most combinations of syringe size and formulation volume, apart from an isolated, large under-provision of delivered volume (i.e. average negative error of $65 \%$ desired volume) when $0.1 \mathrm{ml}$ was used in a $2.5 \mathrm{ml}$ syringe. Of note, the average syringe error for the $1 \mathrm{ml}$ Medicina was acceptable for all volumes, including the smallest volume of $0.05 \mathrm{ml}$. In comparison, all Baxa syringes provided a trend towards unacceptable over-provision (positive error) of delivered volumes when smaller formulation volumes were used, Here the $5 \mathrm{ml}$ syringe over-delivered volume by approximately $30 \%$ when $0.25 \mathrm{ml}$ was attempted, the $2.5 \mathrm{ml}$ syringe yielded a similar error when $0.1 \mathrm{ml}$ was delivered, and the error for the $1 \mathrm{ml}$ syringe became borderline unacceptable (110\%) when $0.1 \mathrm{ml}$ was used.

A limitation of figure 1 is that it provides only an estimation of bias (average error), but not precision. The latter was evaluated using box and whisker plots for each syringe size and formulation type, which revealed poorer overall precision for the Medicina brand. By inspecting the range of volume plots for each syringe size in a sequential manner, we were able to define the approximate limits of accuracy for each syringe. Figure 2 shows an example for the $1 \mathrm{ml}$ syringes. At formulation volumes of $0.05 \mathrm{ml}$ and $0.1 \mathrm{ml}$, the precision for both syringe brands is inadequate, with many values lying outside of the $100 \% \pm 10 \%$ limits (more so for Medicina). However at $0.25 \mathrm{ml}$, the majority of values were now acceptable.

Figure 3 shows the transition points for accuracy of the $2.5 / 3.0 \mathrm{ml}$ syringes. Here, the limit of accuracy was likely to be at a formulation volume of $0.5 \mathrm{ml}$ for both brands. 
Interestingly, the Baxa yielded a large, consistently positive error for cyclosporine, at all volumes up to and including $1.0 \mathrm{ml}$. For the $5 \mathrm{ml}$ syringes, the Medicina demonstrated superior precision, being accurate at formulation volumes of $0.5 \mathrm{ml}$, compared to $1.0 \mathrm{ml}$ for the Baxa (figure $2 \mathrm{~S}$ online supplement).

The multiple regression models did not reveal a systematic pattern for error for any of the physicochemical properties (figure 3S, online supplement), with formulation volume again being the largest determinant of error.

\section{DISCUSSION}

We have evaluated in vitro limits of volume accuracy for two brands of oral syringe, when dispensing common paediatric drug formulations. The largest source of error appeared to be related to the chosen dispensing volume relative to syringe size, rather than the physicochemical properties of the drug formulation itself. Also, the type of error varied between the two syringe brands. Medicina exhibited less bias, but poorer precision (i.e. repeatability) overall; the latter may have been influenced by the larger dead space for this brand. In comparison, Baxa tended to provide a slight positive bias when smaller volumes were administered relative to each syringe size; however this was generally small and the precision (repeatability) was better. Of the two errors, we would suggest that precision is the more important, as this provides less variability with repeated dosing in individual patients.

For each syringe size and brand, there appeared to be a transition point whereby error became unacceptable, which has allowed us to make recommendations for the minimum volume to dispense at each syringe size for both syringe brands (table 2). 
Table 2: Volumetric accuracy of formulation volumes when tested across brands and syringe sizes.

\begin{tabular}{|c|c|c|c|c|c|c|c|}
\hline \multirow[b]{2}{*}{ Brand } & \multirow[b]{2}{*}{$\begin{array}{c}\text { Syringe } \\
\text { Size }\end{array}$} & \multicolumn{6}{|c|}{ Formulation Volume $(\mathrm{mL})$} \\
\hline & & 0.05 & 0.1 & 0.20 & 0.25 & 0.5 & 1.0 \\
\hline Baxa & $1 \mathrm{~mL}$ & - & $-1+$ & & + & + & + \\
\hline Medicina & $1 \mathrm{~mL}$ & - & - & & + & + & + \\
\hline Baxa & $3 \mathrm{~mL}$ & - & - & & $-1+{ }^{*}$ & $+^{*}$ & + \\
\hline Medicina & $2.5 \mathrm{~mL}$ & - & - & & - & + & + \\
\hline Baxa & $5 \mathrm{~mL}$ & - & - & - & & - & + \\
\hline Medicina & $5 \mathrm{~mL}$ & - & - & - & & $-/+$ & + \\
\hline
\end{tabular}

Legend: - inaccurate; - /+ borderline accurate; + accurate; * inaccurate for cyclosporine only. Blank, grey cells occur when the formulation volume was not tested for a given syringe size.

However, these recommendations should be interpreted with some caution for three reasons. First, we did not test small volume increments close to the transition point. Thus, for example, we can see that when dispensing formulations via the $1 \mathrm{~mL}$ syringe (figure 2), volumes of $0.25 \mathrm{~mL}$ are acceptable, whereas volumes of $0.1 \mathrm{~mL}$ are not: however, we do not know if any volumes of administration between these two values (e.g. $0.15 \mathrm{~mL}, 0.2 \mathrm{~mL}$ ) are acceptable. Second, one drug, cyclosporine, appeared to exhibit a consistent error (over-administration) for one syringe brand (Baxa) at volumes where other drugs were accurate for this syringe brand (see figure 3). It is unclear whether this is due to the combination of physicochemical properties not seen with other drugs, or an interaction between a chemical compound in the Baxa syringe not seen in the Medicina brand. Thus, we do not know whether an error of similar magnitude exists for drugs not evaluated in the current study. Third, other factors may influence in vivo error: for example, when administered orally, small 
children may suck on the syringe, thereby increasing drug delivery. Similarly, the effect on volume error of administering these drugs via an enteral feeding tube is unknown.

We chose drugs and volumes to reflect those used in clinical practice. For example, a $5 \mathrm{~kg}$ baby prescribed nifedipine at doses of $200 \mathrm{mcg} / \mathrm{kg}$ would receive volumes of $0.05 \mathrm{~mL}$ (UK nifedipine formulation strength $20 \mathrm{mg} / \mathrm{mL}$ ). From figure 2, this could result in a relative under-dosing in $>50 \%$ of administrations using a Medicina syringe, and an over-dosing in a similar proportion (albeit by a smaller amount) using a Baxa syringe. It is unlikely that a similar dosing inaccuracy for an adult formulation would be acceptable in clinical practice.

To our knowledge, there are very few other studies in the public domain comparing accuracy of oral syringes for different small dose volumes and characteristics of oral liquids. Padden Elliott et al conducted a study looking at the influence of viscosity in three different oral devices: oral syringes, cups and droppers. They found that syringes were the most accurate device in vitro for more highly viscous liquids at a $5 \mathrm{~mL}$ volume, and also in an in vivo sample of 320 volunteers from community pharmacies. However, this team did not look into doses smaller than $5 \mathrm{~mL}$, they did not examine physicochemical properties other then density and viscosity, and they only used one brand of syringe ${ }^{21}$. Other studies examining volumes less than $5 \mathrm{~mL}$ have concluded that oral syringes are more accurate than other devices; however these have tended to concentrate on a limited range of volumes, typically $1.25,2.5$ and $5 \mathrm{~mL}$ (equating to one-quarter, one-half and one teaspoon). ${ }^{22,23}$

One further potential source of error not examined in our study was the effect of rounding when a dose prescription requires a number of decimal places beyond what is available on the syringe. For example, a drug dose of $1.26 \mathrm{~mL}$ cannot be delivered 
adequately when the smallest graduation on a syringe is $0.1 \mathrm{~mL}$. This is common in clinical practice. Morecroft and colleagues audited 1599 inpatient prescriptions of oral liquid medicines, and discovered that $12.5 \%$ could not be given accurately, requiring the use of more than one syringe of different volumes ${ }^{24}$.

Thus we would encourage the pharmaceutical industry, medicines regulators and licensing bodies to mandate the provision of paediatric drug formulations in concentrations that provide adequate dosing volumes to minimise error across the entire spectrum of paediatric practice.

\section{CONCLUSION}

Dosing accuracy with enteral syringes commonly found in the HealthCare systems was heterogenous for different brands, sizes and liquid characteristics especially for small volumes $(0.25 \mathrm{ml}$ and less) which are not uncommon doses in paediatrics.

To improve medication safety in paediatrics, carers should choose the right syringe size for the dose (for small volumes $<0.5 \mathrm{ml}$ use $1 \mathrm{ml}$ size syringes or less if available) and keep to the same brand if properly tested syringes for the intended dose are not available.

Manufacturers need to include as part of the pharmaceutical development plan the validation of the syringes to use with their products especially if dosing volumes are envisaged to be $<0.5 \mathrm{ml}$, and possibly take into account the national guidelines available to reduce the risk of using these devices. 


\section{Acknowledgement:}

We are very grateful to the Evelina London Children's Hospital Pharmacy Department and the School of Pharmacy-UCL for their provision of the oral liquid medicines.

This article is part of the Doctoral Thesis of Sara Arenas-Lopez within the Doctoral Programme in Clinical Medicine and Public Health, Granada University, Spain

Funding: The research leading to these results received funding from the European Commission Seventh Framework Programme (FP7 HEALTH-F5-2010) under grant agreement number 261060 (Global Research in Paediatrics - GRIP) 


\section{References}

1- Lajoinie A, Henin E, Nguyen KA, Malik S, Mimouni Y, Sapori JM, Bréant V, Cochat $P$, Kassai B. Oral drug dosage forms administered to hospitalized children: Analysis of 117,665 oral administrations in a French paediatric hospital over a 1-year period.Int $\mathrm{J}$ Pharm. 2016 Mar 16;500(1-2):336-44. doi: 10.1016/j.ijpharm.2016.01.048. Epub 2016 Jan 22.

2- EMA. Guideline on pharmaceutical development of medicines for paediatric use (EMA/CHMP/QWP/805880/2012 Rev. 1 ) London: European Medicines Agency;

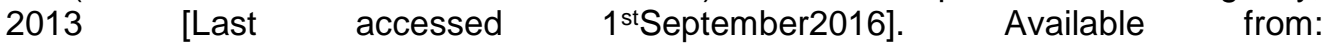
http://www.ema.europa.eu/docs/en GB/document library/Scientific guideline/2013/0 1/WC500137023.pdf.

3- CHMP Reflection Paper: Formulations of choice for the paediatric population EMEA/CHMP/PEG/194810/2005 London: European Medicines Agency; 2006 (Last accessed $1^{\text {st }} \quad$ September 2016). Available from http://www.ema.europa.eu/docs/en GB/document library/Scientific guideline/2009/0 9/WC500003782.pdf

4- WHO.WHO Technical Report Series No.970: World Health Organisation; 2012 (Last accessed $1^{\text {st }}$ September 2016). Available from:http://apps.who.int/medicinedocs/documents/s19833en/s19833en.pdf

5- CHMP. Guideline on the suitability of the graduation of delivery devices for liquid dosage forms Doc. Ref. EMEA/CHMP/QWP/178621/2004 London: European Medicines Agency 2005 [Last accessed $1^{\text {st }}$ September 2016]. Available from: http://www.ema.europa.eu/docs/en GB/document library/Scientific guideline/2009/0 9/WC500003660.pdf

6- FDA. Guidance for Industry: Dosage delivery devices for orally ingested OTC liquid drug products United States: Food and Drug Administration; 2011 [Last accessed $1^{\text {st }}$ September 2016]. Available from: http://www.fda.gov/downloads/Drugs/GuidanceComplianceRegulatorylnformation/Gui dances/UCM188992.pdf.

7- Sobhani P, Christopherson J, Ambrose PJ, Corelli RL. Accuracy of oral liquid measuring devices: comparison of dosing cup and oral dosing syringe. Ann Pharmacother 2008;42(1):46-52

8- Yin $\mathrm{H}$ Malwms et al. Parents; medication administration errors: Role of Dosing instruments and health literacy. Archives of Paediatrics and Adolescent Medicine 2010;164(2):181-6

9- Ryu GS, LeeYJ. Analysis of liquid medication dose errors made by patients and caregivers using alternative measuring devices. J Manag Care Pharm 2012; 18(6):439-45

10- Grie MK, Breitkreutz J, Schubert-Zsilavecz M, Abdel-Tawab M. Dosing accuracy of measuring devices provided with antibiotic oral suspensions. Paediatric and Perinatal Drug Therapy 2007;8(2):61-70

11- British National Formulary for Children (BNF-c): Guidance on Prescribing. BMJ Publishing Group Ltd, RPCH Publications Ltd and The Royal Pharmaceutical Society of Great Britain; 2015-2016. Page 2

12- National Service framework for Children, Young People and Maternity Services: Department of Health; 2004 (Last accessed 1st September 2016). Available from: https://www.gov.uk/government/uploads/system/uploads/attachment data/file/199952 National Service Framework for Children Young People and Maternity Services - Core Standards.pdf

13- Formulating and Administering Children's Medications. In: Improving Medicines for Children in Canada. Council of Canadian Academies. Chapter 4: 89Z113.http://www.scienceadvice.ca/uploads/eng/assessments\%20and\%20publicat ions\%20and\%20news\%20releases/therapeutics/therapeutics fullreporten.pdf)(Acce ssed 1 September 2016) 
14- Promoting Safer Measurement and Administration of liquid medicines via oral and other enteral routes: National Patient Safety Agency September 2007 (Last accessed $1^{\text {st }} \quad$ September 2016) Available from: http://www.nrls.npsa.nhs.uk/resources/?entryid45=59808

15- Oral Syringes: A crucial and economical risk-reduction strategy that has not been fully utilised . United States of America: Institute for Safe Medication Practices; 2009 (Last accessed $1^{\text {st }} \quad$ September 2016). Available from: https://www.ismp.org/newsletters/acutecare/articles/20091022.asp

16- Brown D, Ford JL, Nunn AJ, Rowe PH. An Assessment of dose uniformity of samples delivered from paediatric oral droppers. Journal of Clinical Pharmacy and Therapeutics 2004; 29(6):521-9.

17- British Standard for Medicine Measures- Part 7: Specification for oral syringes delivering doses up to an including 5ml. BS 3221-7:1995. Confirmed December 2011. British Standard Institute.

18- Walsh J, Bickmann D, Breitkreutz J, Chariot-Goulet M. Delivery devices for the administration of paediatric formulations: Overview of current practice, challenges and recent developments. International Journal of Pharmaceutics. 2011;415(12):221-31.

19- Beckett VL, Tyson LD, Carroll D, Gooding NM, Kelsall AW. Accurately administering oral medication to children isn't child's play. Arch Dis Child 2012; 97:838-41

20- USP $29 \quad$ NF24 http://www.pharmacopeia.cn/v29240/usp29nf24s0 c1221.html (Last accessed 0109-16)

21- Padden Elliott J, McConaha J, Cornish N, Bunk E, Hilton L, Modany A and Bucker I. Infleunce of Viscosity and Consumer Use on Accuracy of Oral Medication Dosing Devices. Journal of Pharmacy Technology 2014; 30 (40) 111-117.

22- Grießmann K, Breitkreutz J, Schubert-Zsilavecz M, Abdel-Tawab M. Dosing accuracy of measuring devices provided with antibiotic oral suspensions. Paed Perinat Drug Ther 2007; 8: 61-70

23- Dockhorn S, Feuersenger D, Schuenemann S, Knauf B, Duerr S, Schubert-Zsilavecz M, Abdel-Tawab M. Study of microbial contamination and dosing accuracy of oral dispensers. J Clin Pharm Ther 2010; 35: 279-287

24- Morecroft CW, Caldwell NA, Gill A. Prescribing liquid medication: can the dose be accurately given? Archives of Disease in Childhood, 2013; 98 :831-832 DOI: 10.1136/archdischild-2013-304567 


\section{Figure Legend}

Figure 1: Percentage volume error by syringe brand, syringe size and drug formulation volume. Data are marginal means with $95 \%$ confidence intervals, calculated from Analysis of Variance

Figure 2: Box and whisker plots showing precision for the two syringe brands using $1 \mathrm{~mL}$ syringes at three formulation volumes: $0.05 \mathrm{~mL}, 0.1 \mathrm{~mL}$ and $0.25 \mathrm{~mL}$. Baxa are represented as grey boxes with outliers as crosses, Medicina are white boxes with outliers as open circles. Drug formulation abbreviations: Deion $\mathrm{H} 2 \mathrm{O}$, deionised water; Ca Carb, calcium carbonate; Amox, amoxicillin; Pepp H2O, peppermint water; Nifed, nifedipine; Digox, digoxin; Sytron, sodium iron edentate; One alpha, alfacalcidol; Phenyt, phenytoin; Cyclosp; cyclosporine; Ciproflox, ciprofloxacin.

Figure 3: Box and whisker plots showing precision for the two syringe brands using 2.5 / 3 $\mathrm{mL}$ syringes at two formulation volumes: $0.25 \mathrm{~mL}$, and $0.5 \mathrm{~mL}$. Baxa are represented as grey boxes with outliers as crosses, Medicina are white boxes with outliers as open circles. Drug formulation abbreviations are as for figure 2. 
Figure 1: Percentage volume error by syringe brand, syringe size and drug formulation volume. Data are marginal means with $95 \%$ confidence intervals, calculated from Analysis of Variance

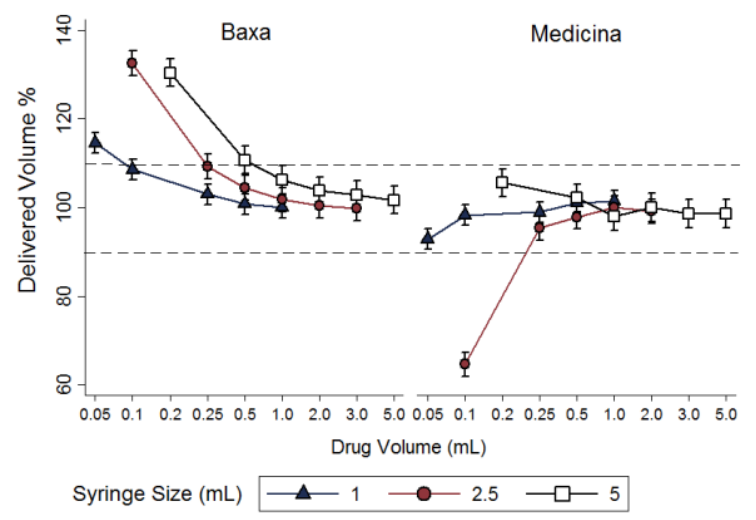


Figure 2: Box and whisker plots showing precision for the two syringe brands using $1 \mathrm{~mL}$ syringes at three formulation volumes: $0.05 \mathrm{~mL}, 0.1 \mathrm{~mL}$ and $0.25 \mathrm{~mL}$. Baxa are represented as grey boxes with outliers as crosses, Medicina are white boxes with outliers as open circles. Drug formulation abbreviations: Deion $\mathrm{H} 2 \mathrm{O}$, deionised water; Ca Carb, calcium carbonate; Amox, amoxicillin; Pepp H2O, peppermint water; Nifed, nifedipine; Digox, digoxin; Sytron, sodium iron edentate; One alpha, alfacalcidol; Phenyt, phenytoin; Cyclosp; cyclosporine; Ciproflox, ciprofloxacin.

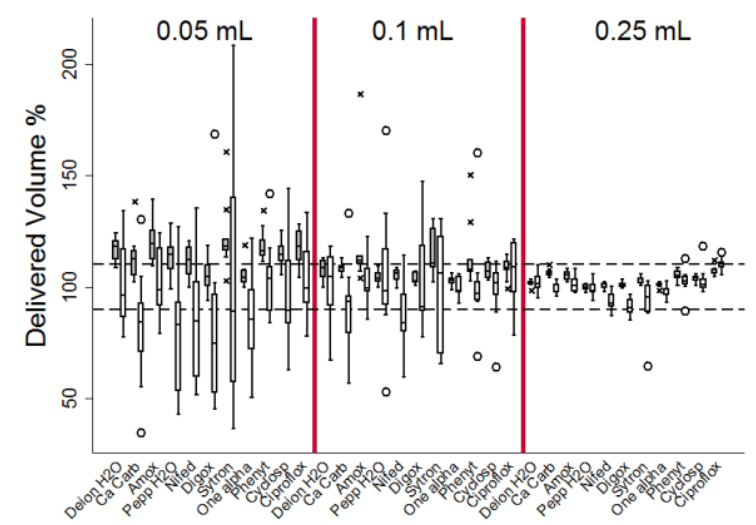


Figure 3: Box and whisker plots showing precision for the two syringe brands using 2.5 / 3 $\mathrm{mL}$ syringes at two formulation volumes: $0.25 \mathrm{~mL}$, and $0.5 \mathrm{~mL}$. Baxa are represented as grey boxes with outliers as crosses, Medicina are white boxes with outliers as open circles. Drug formulation abbreviations are as for figure 2 .

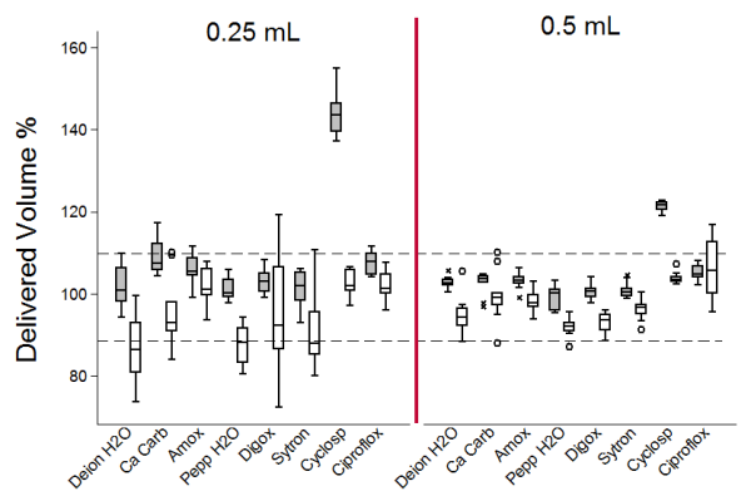

